\title{
Hybrid standalone system for Rural Electrification
}

\author{
Rohini Govindaraju, Saritha Natesan, Lavanya, Ganesh, Abishag Cynthia
}

\begin{abstract}
Renewable energy finds major application in electrification of remote areas where the access to electrical energy from grid is not possible.Renewable energy resources also act as the most important source for electrical energy production to overcome the energy crisis due to lapse of conventional sources and expected to meet the large demand in power all over the world especially in developing country like India. Among the renewable resources, wind \& solar are the most popular ones because of their abundance, ease of accessibility and which can be easily converted to the electricity. This paper presents the design and analysis of a hybrid solar-wind system for domestic purpose in the remote areas of the country where continuous power supply from central grid is a problem
\end{abstract}

Index Terms: Boost converter, Hybrid system, off-grid region Photo Voltaic, SEPIC Converter, Wind energy

\section{INTRODUCTION}

Energy is one of the most important factors for the economic welfare of any nation. In case of developing countries, the increasing energy demand needs huge amount of investments to be met, which is of critical importance now. The continuous increase in human population in the world has created several problems regarding the need of power and increase in toxic gases. One of them is global warming, occurring due to the abundance of $\mathrm{CO} 2$ available in the atmosphere, which is a toxic gas. To reduce this emission into the atmosphere, alternative sources of energy must be used. For the last twenty years, solar energy and wind energy are the alternate and renewable resources that are available in plenty. In hybrid system, wind turbine and photovoltaic cells, offer greater reliability than using them separately because the demand is not entirely based on one resource. For example, on a stormy day when solar energy is low there is likely enough wind energy available to compensate the lack of solar energy. Even in the absence of one source the other source can compensate without uninterrupted power supply. In remote areas, where the grid connected power system does not exist, the standalone system can be used to satisfy the power demand.

\section{PROPOSED HYBRID SYSTEM}

Fig 1 shows the block diagram of solar wind hybrid system which is very useful in remote places and residential complexes which are far away from power plants and which need long transmission lines.The PV module is connected to

Revised Manuscript Received on July 22, 2019

Rohini Govindaraju,Professor, Department of Electrical and Electronics Engineering, Jerusalem College of Engineering, Chennai, India Saritha NatesanDepartment of Electrical and Electronics Engineering, Jerusalem College of Engineering, Chennai, India

Lavanya, Ganesh, AbishagCynthiaDepartment of Electrical and Electronics Engineering, Jerusalem College of Engineering, Chennai, India the DC-DC converter unit to step-up or step down the voltage levels to match the common DC link provided in the system.

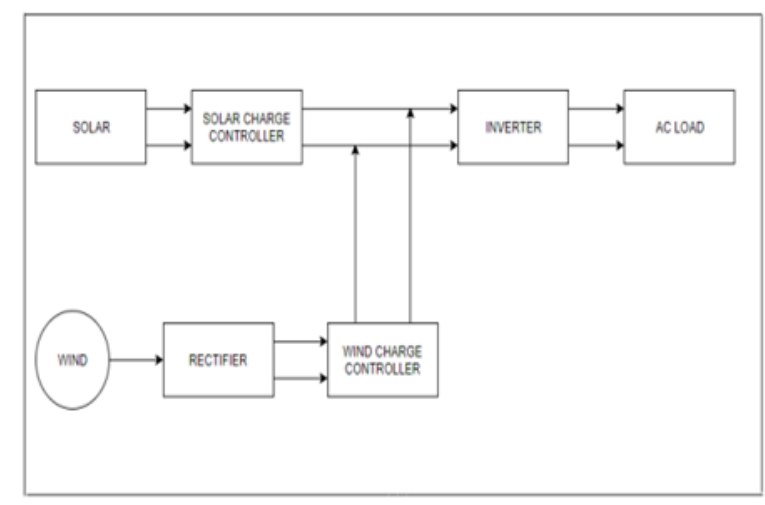

Fig. 1. Block diagram of hybrid power system

The wind turbine is followed by a PMSG generator, which generates an $\mathrm{AC}$ voltage which is further rectified to $\mathrm{DC}$ voltage through a rectifier unit. This DC voltage is now fed to the DC-DC converter circuit in order to regulate the output DC voltage obtained from the turbine and generator setup in accordance with the common DC link. The input for the inverter unit is taken from the DC link and the output obtained (AC voltage through inverter) and is given as supply to the load.

\section{MODELLING OF SYSTEM COMPONENTS}

The standalone hybrid generation system includes a wind generation module and a solar module feeding power to a common dc bus through necessary power electronic converters. Although a hybrid wind-solar electric system demands a higher technology, but the hybrid systems are the best option for a significant improvement in terms of production and efficiency.

\section{A. PV Module}

Solar panels are the types to convert solar power into the electrical power. Solar panels can convert the energy by two ways directly or heat the water from the induced energy. PV (Photo-voltaic) cells are semiconductor structures as in the computer technologies. Fig. 2. Shows the simulation diagram of PV Panel.

Sun light is absorbed with this material and electrons are emitting from this materials. Solar power is converted into the electric power.

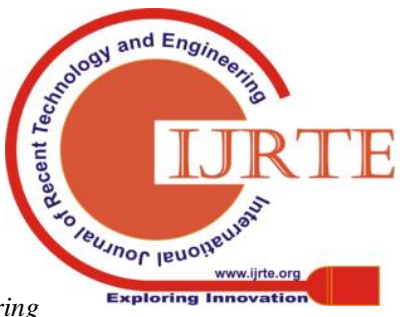




\section{Hybrid standalone system for Rural Electrification}

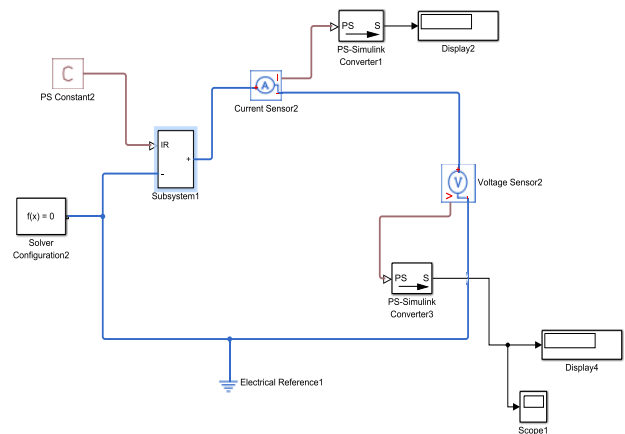

Fig. 2. Simulation diagram of PV Panel

The output power of a solar cell is given by:

$$
\text { Ppv }=\mathbf{V p v} * \mathbf{I p v}
$$

Where,

Ipv - Output current of solar cell (A)

Vpv - Solar cell operating voltage (V)

Ppv - Output power of solar cell (W).

\section{B. Wind genration module}

The wind power generation module basically consists of a wind turbine with the consideration that the blades are rigidly fixed to the turbine. As a result, the pitch angle of the blades also remain fixed. The wind energy which strikes these blades, produces a mechanical torque which further drives a Permanent Magnet Synchronous Generator (PMSG) to produce an electrical output and can be modeled as follows.

The wind turbine output power relating to wind velocity can be represented as:

$$
\operatorname{Pm}=0.5 \rho \operatorname{Ar} \operatorname{Cp}(\lambda, \beta) \operatorname{V\omega }
$$

Where $\mathrm{V \omega} \omega$ - wind velocity, $\beta$ - Blade pitch angle. $\mathrm{Cp}$ - power coefficient,

$\mathrm{Ar}$ - swept area of rotor blades,

$\lambda$ - Tip speed ratio

$\rho$ - Air density

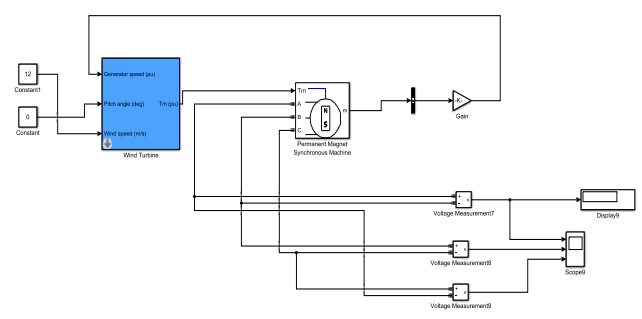

Fig .3. Simulation diagram of Wind Turbine

The coefficient of power $\mathrm{Cp}$ can be expressed as a function of tip-speed ratio $\lambda$ and pitch angle of turbine blade $\beta$, where the tip-speed ratio (TSR) $\lambda$ is expressed by the equation

$$
\lambda=\mathbf{R} \omega \mathbf{r} / \mathbf{V} \omega
$$

Where $\omega r$ - rotational speed of the rotor

$$
\mathrm{R} \text { - the radius of the rotor blades }
$$

\section{PMSG Model}

The equivalent circuit of the PMSG in the d-q synchronous rotating reference frame is used for dynamic modeling of the PMSG.The $\mathrm{d}-\mathrm{q}$ synchronous rotating reference frame voltages are referred with $\mathrm{Vd}, \mathrm{Vq}$, Rs is the resistance on stator side, $\mathrm{Ld}, \mathrm{Lq}$ are the inductances of the generator on the $\mathrm{d}$ and $\mathrm{q}$ axis, is the electrical rotating speed of the generator.

The electromagnetic torque of PMSG is defined by the following model equation,

$\mathbf{T e}=1.5 p\left(\mathbf{L}_{\mathrm{ds}}-\mathbf{L}_{\mathrm{is}}\right) \mathbf{i}_{\mathrm{d}} \mathbf{i}_{\mathrm{q}}+\mathbf{i}_{\mathrm{q}} \boldsymbol{\psi}_{\mathrm{f}}$

Where $\mathrm{p}$ is the number of generator pole pairs.

D. Three phase rectifier

The AC output from the PMSG is converted to DC using a three-phase uncontrolled rectifier whose output voltage Vrec is given by

$$
\mathrm{V}_{\text {rec }}=\mathbf{1 . 6 5} \mathrm{V}_{\mathrm{m}}
$$

Ignoring the diode losses in the diode rectifier, the output power from the converter remains unchanged and is utilized only for rectification process.

\section{E. DC-DC Boost converter}

The DC-DC boost converter controls the variable input voltage from PMSG-Rectifier unit to a fixed DC output voltage. This converter controls the magnitude of output such that it satisfies the requirement of the inverter unit. The equation relating the input and output voltage of this DCDC converter is given by,

$$
\mathbf{V}_{\text {dc }}=\mathbf{V}_{\text {in }}(\mathbf{1}-\mathrm{D})
$$

Where $\mathrm{D}$ is the duty ratio.

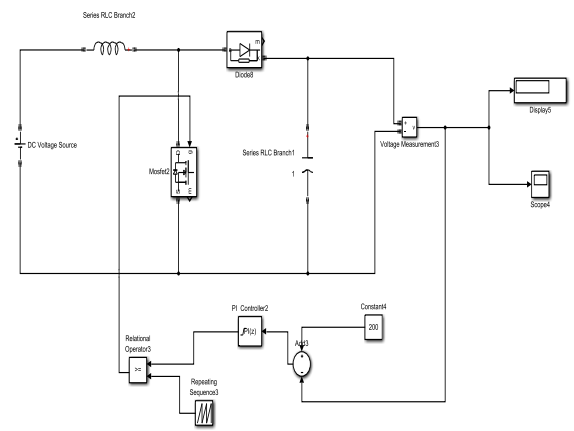

Fig. 4. Simulation diagram of Boost converter F. DC-DC Sepic converter

The SEPIC (single-ended-primary-inductor converter) is a type of DC to DC converter that allows the electrical potentialat its output to be greater thanor less than at its input. The equation relating the input and output voltage of this DC-DC converter is given by,

Vout $=D^{*} \operatorname{Vin} /(1-D)$

Where $\mathrm{D}$ is the duty ratio. 


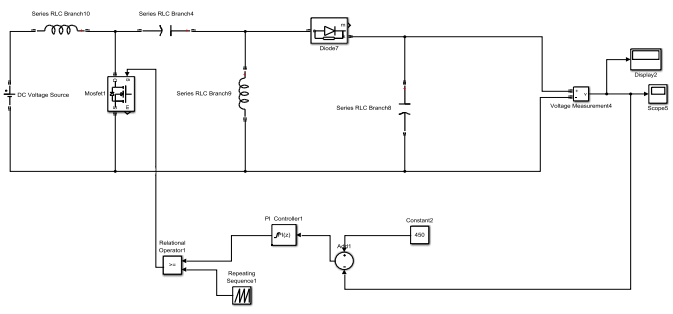

Fig. 5. Simulation diagram of Sepic converter

\section{G. P-I controller}

$\mathrm{P}-\mathrm{I}$ controller is mainly used to eliminate the steady state error resulting from $\mathrm{P}$ controller. However, in terms of the speed of the response and overall stability of the system, it has a negative impact. This controller is mostly used in areas where speed of the system is not an issue. Since P-I controller has no ability to predict the future errors of the system it cannot decrease the rise time and eliminate the oscillations. If applied, any amount of I guarantees set point overshoot.

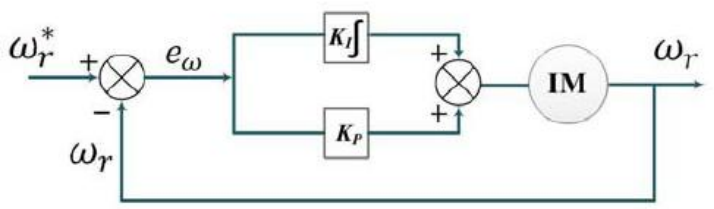

Fig. 6. Block diagram of PI controller

\section{H. Inverter}

The DC voltage at the DC bus is then converted to AC with the help of a Sinusoidal Pulse Width Modulated (SPWM) inverter. If ton is the turn-on time of the switch, the rms output voltage can be determined by:

$$
V_{0}=\operatorname{Vs}\left[\sum(2 \operatorname{ton} / T)\right]^{\wedge}(1 / 2)
$$

The pulses are produced by amplitude modulation and the modulation index is defined as:

$$
\mathrm{Ma}=\mathrm{Vcon} / \mathrm{Vc}
$$

where,

Vcon - Peak magnitude of control signal (modulating sine wave)

Vc - Peak magnitude of carrier signal (triangular signal)

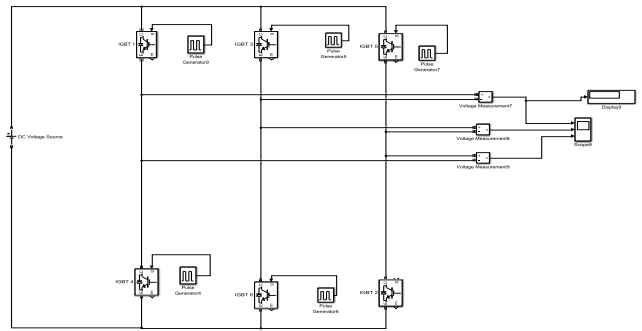

Fig. 7. Simulation diagram of Three phase Inverter

\section{SIMULATION RESULTS}

\subsection{Wind Turbine Module}

The wind turbine is simulated in Simulink using the above modelling equations; where the inputs to the model are wind speed $12 \mathrm{~m} / \mathrm{s}$; pitch angle 0 , rotor diameter, air density and turbine speed.

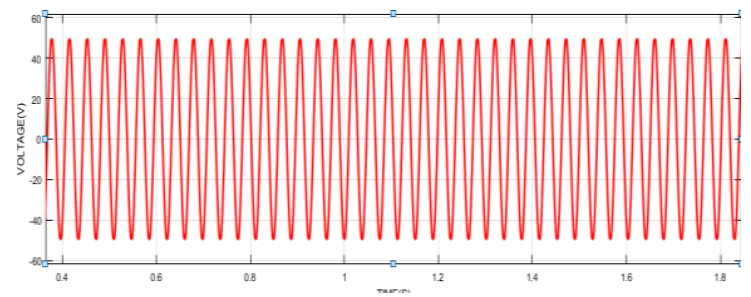

Fig. 8. Output of wind turbine

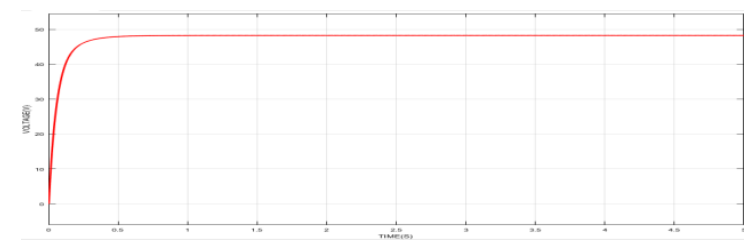

Fig. 9. Output of Wind turbine with Rectifier

\subsection{PV Module}

The PV module produces 48v. The I-V characteristics for different solar irradiation values are given by. The output voltage of PV array is given by

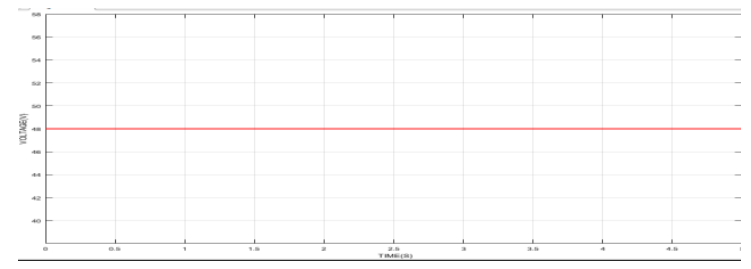

Fig. 10. Output of Solar Panel

\section{Boost and Sepic with PI Controller}

P-I controller is mainly used to eliminate the steady state error resulting from $\mathrm{P}$ controller. However, in terms of the speed of the response and overall stability of the system, it has a negative impact. The output of Boost converter with PI Controller is given by

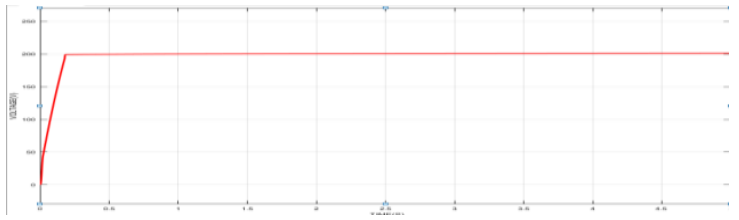

Fig. 11. Output of Boost converter with PI controller

The output of the boost 
converter 200v is given as the input for Sepic converter and the output of the Sepic converter with PI controller is given

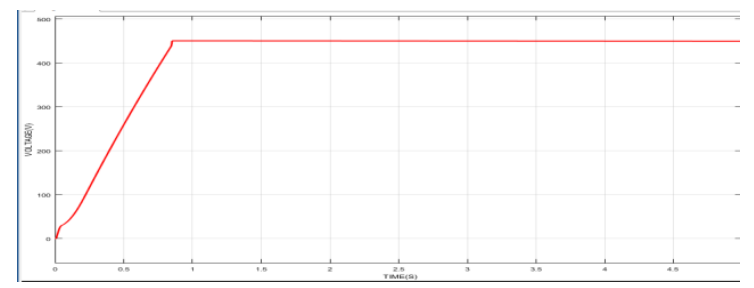

Fig. 12. Output of Sepic converter with PI controller

\section{E. Load with three phase inverter}

The inverter converts $\mathrm{DC}$ to $\mathrm{AC}$ source, which is connected to the three phase $\mathrm{R}$ load. The $\mathrm{R}$ load which is connected may be Incandescent lamp, electrical heaters etc. In resistive load the current is in phase with the voltage, the current rises immediately to its steady-state value, without first rising to a higher value. It can have a little inrush current. Fig. 13 shows the simulation diagram of Inverter with R load

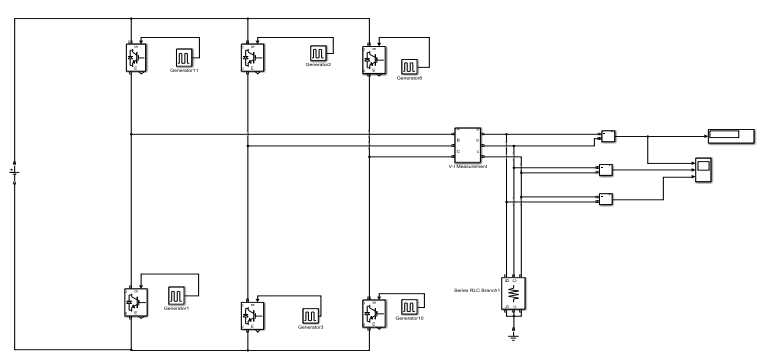

Fig. 13 Simulation diagram of Inverter with R load

\section{HYBRID SYSTEM}

A hybrid arrangement of combining the power harnessed from both the wind and the sun can be a much more reliable and realistic power source.

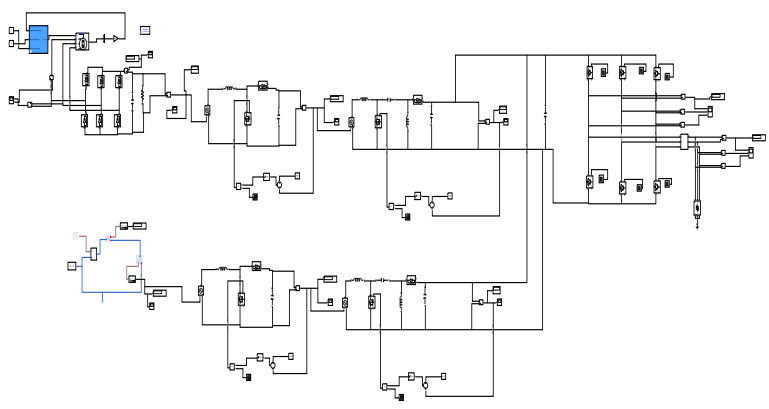

Fig. 14 Simulation diagram of Hybrid system

Hybrid systems are usually built for design of systems with lowest possible cost and also with maximum reliability.

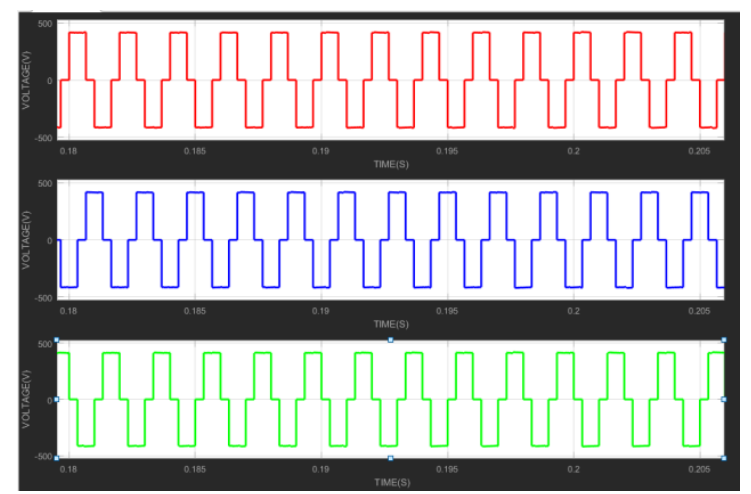

Fig. 15. Output of Hybrid system

\section{CONCLUSION}

In this paper, the modelled hybrid power generation system is devised to achieve the task of increasing the power extraction over a wide range of wind velocities and solar intensities and provide an uninterruptable power to meet the demand. Also, standalone Renewable Energy production can be a better alternative to conventional energy production particularly in rural areas and remote locations, where access to electricity is difficult. PV array and wind turbine are simulated with its associated converters are designed and simulated using MATLAB.

\section{REFERENCES}

[1] P. Thounthong and S. Rael, "The benefits of hybridization," IEEE Ind. Electron. Mag., vol. 3, no. 3, pp. 25-37, Sep. 2018.

[2] S. M. Muyeen, R. Takahashi, T. Murata, and J. Tamura, "Integration of an energy capacitor system with a variable-speed wind generator," IEEE Trans. Energy Convers., vol. 24, no. 3, pp. 740-749, Sep. 2018

[3] L. Wang and D. J. Lee and W. J. Lee and Z. Chen, ' Analysis of a novel autonomous marine hybrid power generation/energy storage system with

a high-voltage direct current link", journal of power source, Volume 185 , Issue 2, Pages 1284-1292, 1 December 2017.

[4] X.Yingcheng and T. Nengling, "Review of contribution to frequency control through variable speed Wind Turbine", Renewable Energy, Volume 36, Issue 6, Pages 1671-1677, June 2017

[5] D. J. Lee and L. Wang, 'Small-Signal Stability Analysis of an Autonomous Hybrid Renewable Energy Power Generation/Energy Storage System Part I: Time-Domain Simulations", IEEE Transaction on Energy Conversion, Vol. 23, No. 1, March 2017.

[6] H. M. K. Al-Masri and M. Ehsani, "Impact of wind turbine modeling on a hybrid renewable energy system," 2016 IEEE Industry Applications Society Annual Meeting, Portland, OR, 2017, pp. 1-8.

[7] J. Plaza Castillo, C. DazaMafiolis, E. Coral Escobar, A. Garcia Barrientos and R. Villafuerte Segura, "Design, Construction and Implementation of a Low Cost Solar-Wind Hybrid Energy System," in IEEE Latin America Transactions, vol. 13, no. 10, pp. 3304-3309, Oct. 2017.

[8] F. Guérin, D. Lefebvre, A. B. Mboup, J. Y. Parédé, E. Lemains and P. A. S. Ndiaye, "Hybrid Modeling for Performance Evaluation of Multisource Renewable Energy Systems," in IEEE Transactions on Automation Science and Engineering, vol. 8, no. 3, pp. 570-580, July 2016.

[09] G. Rohini and V. Jamuna, "PLL Based Energy Efficient PV System with Fuzzy Logic Based Power Tracker for Smart Grid Applications," The Scientific World Journal, vol. 2016, Article ID 2708075, 20 pages, 2016

[10]A. Jenifer., N. R. Newlin, G. Rohini. and V. Jamuna., "Development of Matlab Simulink model for photovoltaic arrays," 2012 International Conference on Computing, Electronics and Electrical Technologies (ICCEET), Kumaracoil, 2012, pp. 436-442

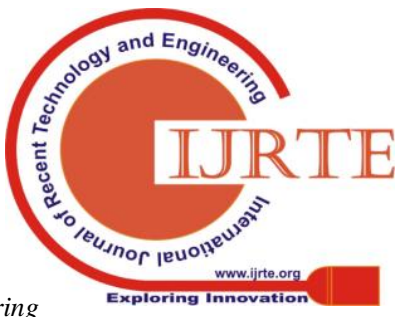

